BMJ Open Sport \& Exercise Medicine

\title{
Pursuit of performance excellence: a population study of Norwegian adolescent female cross-country skiers and biathletes with disordered eating
}

\author{
Ingvild Pettersen, ${ }^{1,2}$ Erik Hernæs, ${ }^{3}$ Finn Skårderud ${ }^{2,4,5}$
}

To cite: Pettersen I, Hernæs $E$, Skårderud $F$. Pursuit of performance excellence: a population study of Norwegian adolescent female crosscountry skiers and biathletes with disordered eating. BMJ Open Sport Exerc Med 2016;2:e000115. doi:10.1136/bmjsem-2016000115

- Prepublication history for this paper is available online. To view these files please visit the journal online (http://dx.doi.org/10.1136/ bmjsem-2016-000115).

Accepted 19 July 2016

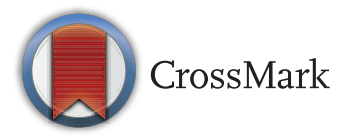

${ }^{1}$ Lovisenberg Hospital, Oslo, Norway

${ }^{2}$ Norwegian Olympic and Paralympic Committee, Oslo, Norway

${ }^{3}$ Ragnar Frisch Centre for Economic Research, Oslo, Norway

${ }^{4}$ Norwegian School of Sport Sciences, Oslo, Norway

${ }^{5}$ Institute of Eating Disorders, Oslo, Norway

Correspondence to Ingvild Pettersen;

ingvild.pettersen1@gmail.com

\section{ABSTRACT}

Aim: To examine the prevalence of disordered eating (DE) among the total population of Norwegian female cross-country skiers and biathletes at the junior level, and to determine whether sociodemographic characteristics predict DE among athletes.

Methods: A cross-sectional population study of Norwegian female junior cross-country skiers and biathletes $(n=262)$, with a response rate of $86 \%$. Descriptive statistics and logistic regression analyses explored the prevalence of DE and its relation to sports, competitive age groups, competitive status and education. DE was defined as meeting at least 1 of the following criteria from 2 subscales of the Eating Disorder Inventory-2: the Drive for Thinness score $\geq 15$ and/or the Body Dissatisfaction score $\geq 14$.

Results: $18.7 \%$ of the athletes had DE. There was no significant difference in the occurrence of DE between the sports or the competitive age groups. Athletes who had dropped out of sports had a significantly higher occurrence of $\mathrm{DE}$, while athletes who attended upper secondary schools of elite sports or general studies had a significantly higher occurrence of DE based on Drive for Thinness.

Conclusions: The number of female cross-country skiers and biathletes with DE is higher than that found in previous similar studies using the same screening instruments. Type of education and competitive status are significant predictors of DE, indicating that DE in addition to having adverse effects on an athlete's health, may also lead to early dropout of sport. This indicates that health and achievement are not always compatible within sports.

\section{INTRODUCTION}

Disordered eating (DE) and clinical eating disorders (ED) are well-known health problems among adolescents, and young athletes do not seem to be exempt from this. ${ }^{12}$ While athletes often are positively associated with good health considering the various benefits of being physically active, ${ }^{3}{ }^{4}$ research indicates that health and performance may not be compatible within sports. ${ }^{5}$

\section{What are the new findings?}

- Disordered eating may be a significant predictor of sport dropout.

- Attending upper secondary schools of sports specialisation was not a predictor of disordered eating as opposed to attending upper secondary schools of elite sports. Attending elite sport schools may thus constitute a health risk for adolescent female athletes.

There is solid empirical evidence of the relatively high prevalence of $\mathrm{DE}$ and $\mathrm{ED}$ in sports in general. ${ }^{5}{ }^{6} \mathrm{DE}$ refers to a wide range of abnormal eating behaviours such as restriction of food and dieting, binge eating, vomiting and abuse of diuretics, laxatives, diet pills and a morbid preoccupation with body weight and shape. ${ }^{7}$ DE differs from ED in the frequency of behaviour and level of severity, and can lead to Other Specific Feeding or Eating Disorders (OSFED) and Unspecific Feeding or Eating Disorders (UFED), or clinical ED such as anorexia nervosa and bulimia nervosa. ${ }^{8}$

Many studies indicate a higher prevalence of DE and ED among adolescent and adult elite athletes than in non-athlete controls. $^{2} 5^{9-11}$ This is particularly prevalent in weight-sensitive sports where low weight and leanness are considered as a competitive advantage. $^{5} \begin{array}{llll}7 & 10 & 12 & \text { In contrast, other studies }\end{array}$ have not found support for this, especially in high school athletes. ${ }^{6}$ 13-17 The only consensus today is that female athletes have a higher risk of DE and ED than males. ${ }^{2} 61011$

The risk factors of ED in sports are multiple and complex. ${ }^{1819}$ The hours of physical activity have no clear correlation with the risk of developing ED. ${ }^{20}{ }^{21}$ The competitive nature of sport has therefore been emphasised as many athletes are in a constant pursuit of performance excellence. Since 
performance is at the core of elite endurance sports, an extreme focus on nutrition and the pursuance of ideal body composition and weight may emerge, ${ }^{22}$ as this is commonly believed to enhance performance. Some studies report that a gradual approach to weight loss may improve the performance outcome, ${ }^{23}{ }^{24}$ but this is dependent on the strategy used for weight loss and recovery, the magnitude of the weight loss and the initial percentage of body fat of the athlete. ${ }^{25}{ }^{26}$ In contrast, other studies indicate that rapid and extreme weight loss may actually impair performance, ${ }^{24}{ }^{27}$ and can result in DE or ED. ${ }^{28} 29$ ED have severe physical and psychosocial consequences, ${ }^{30} 31$ and are therefore not compatible with sports performance in the long run.

Whereas the prevalence of DE among adolescent athletes is fairly well documented, there is a lack of studies with representative samples of adolescent athletes and the risk factors that may predispose or contribute to the development of DE. We therefore assessed the prevalence of DE among the total population of Norwegian adolescent female cross-country skiers and biathletes, and possible sociodemographic predictors of DE. Cross-country skiing and biathlon were chosen based on their particular vulnerability to DE since body weight and leanness are considered as important determinants for performance. ${ }^{32} 33$ The prevalence of DE within these sports is as yet unknown. ED have a peak risk of onset in adolescence ${ }^{34} 35$ thus early identification of young female athletes is important as they have substantial risk of DE which may lead to ED. ED increase the risk of morbidity and mortality. ${ }^{30} 31$ This further emphasises the importance of determining the prevalence and possible predictors of DE in adolescent female athletes in order to estimate the magnitude of the problem, with the ultimate goal of providing data supporting and improving earlier screening interventions.

The research questions were as follows:

1. How prevalent is DE among the total population of female cross-country and biathlon athletes at the junior level in Norway?

2. Are sociodemographic characteristics such as type of sport, competitive age group, education and competitive status possible predictors of DE?

\section{METHODS}

\section{Participants}

The total population of female cross-country skiers and biathletes in Norway at the junior level from the 2009 to 2010 season were invited to participate after the end of the season. Inclusion criteria included the top 30 athletes in at least one of the Norwegian Junior Cup races from season 2009 to 2010 within the appropriate competitive age group and sport. Some athletes competed in both athletic disciplines. The study was conducted with a web-based census survey through Questback. Data were collected in 2011. Out of 262 athletes invited, 225 responded, resulting in a response rate of $86 \%$.

\section{Assessment procedures}

\section{Questionnaire}

A questionnaire including a battery of assessment questions regarding sociodemographic variables and Eating Disorders Inventory-2 (EDI-2) was administered to the respondents. The sociodemographic variables consisted of type of sport, competitive age group, competitive status and type of school. Within type of school, upper secondary school (USS) consisted of general studies, sports specialisation schools (SSS) and elite sport schools (ESS). The latter two are designed for athletes by combining education and sports. SSS are public schools, while most ESS are privately financed and more selective by accepting only highly talented athletes.

The EDI-2 assesses ED and subclinical eating problems. ${ }^{36}$ The Norwegian version is not validated, but the original EDI-2 has a high reliability and validity. ${ }^{36-39}$ While consisting of 11 subscales, only the Drive for Thinness (DT, $\alpha=0.91$ ) and the Body Dissatisfaction (BD, $\alpha=0.91$ ) scales were used as they are most strongly correlated with eating-related pathology, and the most sensitive detector of ED. ${ }^{36}{ }^{40}$ The DT assesses excessive concern with dieting, preoccupation with weight, thinness and fear of weight gain-and constitutes the 'morbid fear of fatness' characteristics of ED. The BD assesses the degree of body dissatisfaction, and addresses the 'body image disturbance' of ED. ${ }^{36}$

\section{Statistical analyses}

The data were subject to statistical analysis through IBM SPSS Statistics V.19.0. Results are expressed as absolute numbers $(\mathrm{N})$ and percentage $(\%)$ for the categorical data. Logistics regressions were used to examine how sociodemographic variables predict DE. All analyses are conducted with the same set of independent variables.

DE is measured through three dependent dichotomous variables. The first dependent variable, EDI, classified DE if the athlete scored at or above the mean score for known anorectics on the DT scale $\geq 15$ and/or BD scale $\geq 14,{ }^{41}$ which are previously used selection criteria when investigating female elite athletes with DE. ${ }^{7} 1642$ Since EDI assesses DE through two different scales measuring different aspects of ED, each scale was also tested separately. The second variable, EDI-DT, classified DE by a cut-off score on the DT scale $\geq 15$. The third variable, EDI-BD, classified DE by a cut-off score on the BD scale $\geq 14$. Scores below the cut-offs on each dependent variable were registered as not having $\mathrm{DE}$. ORs are given with $95 \%$ CI. The significance level was set at 0.05 . No statistical method for handling missing cases was employed, as the present study had no missing data.

\section{RESULTS}

\section{Disordered eating}

The distribution of the 225 respondents was $52 \%$ crosscountry skiers $(\mathrm{N}=118), 36.4 \%$ biathletes $(\mathrm{N}=82)$ and $11.1 \%(\mathrm{~N}=25)$ athletes competing in both sports. The 
prevalence of athletes with $\mathrm{DE}$ in the total sample was $18.7 \%(\mathrm{~N}=42$, table 1$)$. A total of $8 \%(\mathrm{~N}=18)$ scored at or above the cut-off score for DT along with $16.9 \%$ $(\mathrm{N}=38)$ on $\mathrm{BD}$ on the EDI-2.

\section{Sociodemographic characteristics}

A higher percentage of athletes with DE were found among those who competed in both sports compared with the other sports (table 1). There is more than a twice as high prevalence of DE from the first and second competitive age groups, but the increase is not linear. Almost one in three athletes attending USS of elite sports had DE, which is almost twice as high compared with the other types of USS where the prevalence of DE was quite similar. The only exception was for those who did not study, who had no DE at all. An important finding is that $\mathrm{DE}$ among athletes who are no longer active is almost three times higher than among those who are still active (table 1).

\section{Sociodemographic predictors of DE}

The strongest predictor of DE, measured by EDI, was no longer being active $(\beta=1.08)$, compared with still being active (table 2). This was a consistent finding in all three models, with $(\beta=1.71)$ in EDI-DT and $(\beta=2.25)$ in EDI-BD. Attending USS of general studies $(\beta=2.62)$ was the strongest predictor of DE measured by EDI-DT compared with attending USS of sports specialisation. Athletes attending USS of elite sports had a significantly higher occurrence of $\mathrm{DE}(\beta=2.25)$ than those who attended USS of sports specialisation. Age and sport were not found to be significant predictors of an athlete's risk of DE in the three models (table 2).

Table 1 Total percentage and number of respondents with $\mathrm{DE}$ within the sociodemographic variables

\begin{tabular}{lcc}
\hline Descriptive categories & N & DE \\
Totals & $\mathbf{4 2}$ & $\mathbf{1 8 . 7}$ \\
\hline Type of sport & & \\
Cross-country skiing & 18 & 15.3 \\
Biathlon & 18 & 22.0 \\
$\quad$ Both sports & 6 & 24.0 \\
Competitive age group & & \\
Women17 & 7 & 10.4 \\
Women18 & 15 & 25.9 \\
Women 19+ & 20 & 20.0 \\
Type of school & & \\
$\quad$ USS, sports specialisation & 16 & 16.3 \\
$\quad$ USS of elite sports & 13 & 28.9 \\
$\quad$ USS of general studies & 8 & 17.8 \\
$\quad$ Higher education & 5 & 16.7 \\
$\quad$ Non-student & 0 & 0.0 \\
Competitive status & & \\
$\quad$ Active & 28 & 14.7 \\
$\quad$ Not active & 14 & 40.0 \\
\hline DE, disordered eating; USS, upper secondary school. &
\end{tabular}

\section{DISCUSSION}

\section{Prevalence of DE}

In total, $18.7 \%$ of the athletes in this study had DE. This result is relatively similar compared with less wellcontrolled studies with age-matched high school athletes with a prevalence of $\mathrm{DE}$ of $20.0 \%$ within leanness sports ${ }^{43}$ and $18.7 \%$ in endurance sport. ${ }^{17}$ However, these studies are not directly comparable due to the usage of other screening instruments.

A recent study of Norwegian adolescent female athletes competing in leanness and non-leanness sports conducted by Martinsen $e t a l^{16}$ reported a lower risk of DE than was found in this study by using the same questionnaire, EDI-2 and cut-off scores. Martinsen et $a l^{16}$ found no difference in the prevalence of DE between leanness and non-leanness sports and only $2.3 \% \quad(\mathrm{~N}=5)$ and $16.6 \%(\mathrm{~N}=36)$ of the female athletes scored over the cut-off score for DT and BD on the EDI-2, compared with $8 \%(\mathrm{~N}=18)$ and $16.9 \%(\mathrm{~N}=38)$ in this study.

\section{The pursuit of performance excellence}

The prevalence of DE was higher on the BD scale $(16.9 \%)$ than on the DT scale $(8 \%)$. This implies that the athletes were mostly dissatisfied with their bodies as opposed to having excessive concerns regarding preoccupation with weight, dieting and a fear of gaining weight. This should be taken seriously as research implies that a risk factor in developing clinical or subclinical ED is based on a dissatisfaction with one's body and weight. ${ }^{44}$ Body dissatisfaction may lead to dieting which increases the risk of initiation and maintenance of ED. ${ }^{45}$ Excessive concerns regarding weight, body and appearance seem to be important maintenance factors of $\mathrm{ED}$, and the onset of ED or DE normally starts with dieting behaviours. ${ }^{46}{ }^{47}$

The high prevalence of athletes with DE in this study may be related to the pursuit of performance excellence, where weight loss and dieting are used as the means to improve athletic outcomes in response to demands for thinness in lean sport. ${ }^{16}{ }^{22}$ Cross-country skiers and biathletes are vulnerable to this aspect since a high fat mass is considered a disadvantage by decreasing efficiency of movements. ${ }^{22}$ Thus, it may be desirable to diet in order to obtain a lean body. There are, however, inconsistent findings regarding the weight loss effect on the athlete's performance. While some studies indicate an improvement, others report on an impaired health and performance. ${ }^{24} 27 \quad 28$ This may imply that the athletes identified with DE may inadvertently be harming their health as well as their athletic achievements.

\section{Sociodemographic characteristics and DE}

Neither age nor type of sport turned out to be significant predictors of DE. This was expected as both sports are weight and lean dependent, and therefore have relatively similar risks. Age is not significant, but this may be caused by the athletes being past the peak risk of onset for ED that seem to occur between childhood and late 
Table 2 Logistic regression of DE with sociodemographic variablest

\begin{tabular}{|c|c|c|c|c|c|c|c|c|c|}
\hline \multirow[b]{2}{*}{ Explanatory } & \multicolumn{3}{|l|}{ EDI¥ } & \multicolumn{3}{|c|}{ EDI-DT§ } & \multicolumn{3}{|c|}{ EDI-BDף } \\
\hline & OR & $95 \% \mathrm{Cl}$ & p Value & $\overline{\text { OR }}$ & $95 \% \mathrm{Cl}$ & $p$ Value & $\overline{\text { OR }}$ & $95 \% \mathrm{Cl}$ & p Value \\
\hline \multicolumn{10}{|l|}{ Sociodemographic variables } \\
\hline Biathlon & 1.54 & 0.68 to 3.52 & 0.305 & 0.82 & 0.23 to 2.88 & 0.751 & 1.39 & 0.59 to 3.27 & 0.455 \\
\hline Both sports & 2.00 & 0.66 to 6.06 & 0.219 & 0.60 & 0.07 to 5.51 & 0.653 & 2.11 & 0.69 to 6.39 & 0.189 \\
\hline \multicolumn{10}{|l|}{ Age } \\
\hline Women 17 & 0.51 & 0.17 to 1.48 & 0.215 & 0.40 & 0.08 to 1.95 & 0.257 & 0.58 & 0.20 to 1.73 & 0.331 \\
\hline Women 18 & 1.34 & 0.55 to 3.28 & 0.522 & 0.40 & 0.10 to 1.64 & 0.203 & 1.53 & 0.62 to 3.78 & 0.359 \\
\hline \multicolumn{10}{|l|}{ Competitive status } \\
\hline Not active & 2.94 & 1.22 to 7.10 & $0.016^{*}$ & 5.50 & 1.56 to 19.42 & $0.008^{\star}$ & 2.58 & 1.04 to 6.41 & $0.042^{*}$ \\
\hline \multicolumn{10}{|l|}{ Education } \\
\hline USS elite sports ${ }^{\star *}$ & 2.40 & 1.00 to 5.89 & 0.055 & 9.44 & 1.74 to 51.31 & $0.009^{*}$ & 1.84 & 0.74 to 4.56 & 0.189 \\
\hline USS of general studies & 1.42 & 0.51 to 3.97 & 0.503 & 13.79 & 2.34 to 81.35 & $0.004^{*}$ & 1.32 & 0.47 to 3.66 & 0.597 \\
\hline Higher education & 1.04 & 0.30 to 3.57 & 0.955 & 2.96 & 0.35 to 24.72 & 0.317 & 0.61 & 0.15 to 2.55 & 0.501 \\
\hline Non-student & 0.00 & 0.00 & 0.999 & 0.00 & 0.00 & 0.999 & 0.00 & 0.00 & 0.999 \\
\hline Constant & 0.12 & & 0.00 & & & 0.000 & 0.12 & & 0.000 \\
\hline $\mathrm{R}^{2}$ (Nagelkerke) & 0.15 & & & & & & 0.13 & & \\
\hline $\mathrm{R}^{2}$ (Cox and Snell) & 0.09 & & & & & & 0.08 & & \\
\hline -2 Log likelihood & 195.17 & & & & & & 186.72 & & \\
\hline$x^{2}$ & 21.44 & & & & & & 17.64 & & \\
\hline
\end{tabular}

${ }^{*} \mathrm{p}<0.05$.

†Logistic regression analysis with cross-country skiing, women in the age group of $19+$, active competitive status, and USS of sports specialisation as baseline categories.

fEDI is based on a cut-off score $\geq 15$ on EDI-DT and/or the cut-off score $\geq 14$ on EDI-BD.

$\S E D I-D T$ is based on a cut-off score $\geq 15$ on EDI-DT.

TEDI-BD is based on a cut-off score $\geq 14$ on EDI-BD.

${ }^{* *}$ Private USS combining education and sports for highly talented athletes.

$\mathrm{BD}$, body dissatisfaction; DE, disordered eating; DT, drive for thinness; EDI, eating disorders inventory; USS, upper secondary school.

adolescence, ${ }^{34} 35$ as the majority of the sample was in their later adolescent and early adulthood. Moreover, age is often categorised as non-specific because age is related to other psychiatric disorders than just ED. ${ }^{48}$

Athletes who were no longer active had a significantly higher occurrence of DE based on EDI, EDI-DT and EDI-BD than those who were still active, implying that DE may be caused by a morbid fear of fatness and body image disturbances. There is a lack of research conducted on dropout, and while dropout is probably caused by multiple interacting factors, Sundgot-Borgen and Torstveit $^{10}$ report that $30 \%$ of female athletes in their study considered ending their career due to problems concerning weight and ED. Since 4 in 10 dropout athletes had DE, this indicates that DE may cause early sport dropout. In that case, the negative impact of sports causing DE is generally underestimated by looking only at the prevalence among those still active.

In this study, athletes attending USS of elite sports or general studies had a high and significant occurrence of DE measured by the EDI-DT, but this difference is not significant when controlled for other characteristics. ESS athletes had a higher frequency of DE than athletes attending general studies, with an almost twice as high OR. There is a lack of studies looking at the prevalence of DE among athletes in different types of USS and, to the best of our knowledge, this is the first study of the variation of DE across different types of schools. Martinsen $e t a l^{16}$ found a significantly higher prevalence of DE among controls at general studies as opposed to athletes at ESS, adding support to previous research. ${ }^{6} 14$ This study is not in line with these findings. However, the studies are not directly comparable as their control group was made up of non-athletes, which may explain the different results.

The high occurrence of DE within these schools may be related to their environments. ESS are known for having a high performance pressure. This can result in a performance-focused climate that can predispose to the use of dieting methods in order to improve their performance if the athlete does not cope with the pressure. In addition, the students often move away from home to attend these schools, which may increase the risk of poor nutrition without the parental control. A similar pattern could apply to athletes in general studies, as they may experience high academic pressure in addition to sport performance pressure. Furthermore, students in general studies are often unable to train within school hours as in ESS and SSS, which may increase the pressure. These factors can result in a total strain that the athlete does not master, or maladaptive perfectionism, which in some cases may increase the risk of ED. ${ }^{49}$

Finally, the prevalence of DE was almost twice as high at the ESS as compared with SSS. These are two 
presumably similar types of USS, and it is therefore an interesting finding that ESS have a significantly increased risk of ED as opposed to SSS.

\section{Methodological considerations}

Being based on the total population of Norwegian female cross-country skiers and biathletes at the junior level is the main strength of this study, as this results in more representative and accurate statistics. The high response rate of $86 \%$ strengthens the validity of the results, and may be considered as representative of the target population. The validity of the findings is further strengthened by the fact that there are no missing data, thus providing a sound basis for generalisation to other female junior athletes competing within endurance sports. However, one cannot draw conclusions regarding the causality due to cross-sectional data. Reversed causality cannot be excluded. We do not know whether the sport itself may lead to DE, or whether the sport is an attractive arena for people with DE.

The use of conservative cut-off scores in EDI-2 strengthens the study by minimising the risk of identifying false-positive athletes with DE. However, clinical interviews are needed to identify clinical ED within those who scored at or above the cut-off scores. The use of dichotomisation of variables in the study gives a transparent analysis, but also leads to a loss of information. ${ }^{50}$ However, inspection of the data reveals that the exact location of cut-off points is not crucial, since there is no concentration of observation around the chosen cut-off points.

The EDI-2 is limited by being developed before OSFED and UFED was a diagnosis of ED in Diagnostic and Statistical Manual of Mental Disorders, Fifth Edition (DSM-5), and may provide an inaccurate picture of athletes with DE. Errors of self-report must be taken into consideration when analysing the results. Respondents will not necessarily report their actual attitudes and beliefs, which can make it difficult to distinguish between athletes who are psychologically healthy and those who deny their psychological problems. ${ }^{51}$

\section{CONCLUSION AND FURTHER RESEARCH}

A large proportion of Norwegian adolescent female cross-country skiers and biathletes had DE, and this study reports a higher prevalence than previous studies with similar samples and the same screening instruments. The athletes with DE were mainly struggling with body image disturbances.

The sociodemographic characteristics are to some extent predictors of DE. Cross-country skiers and biathletes, along with their respective competitive age groups, had the same occurrence of DE. Athletes attending either USS of elite sports or general studies had a significantly higher occurrence of DE compared with other schools. $\mathrm{DE}$ seems to be a strong predictor of dropout, as almost half of the athlete dropouts were identified with DE.
The ultimate goal of research on DE and ED should be to improve interventions and ultimately reduce the prevalence. To better understand the causal relationship of the predictors of DE, longitudinal studies are needed on both male and female athletes younger than the junior competing level. There is a need for theory-based research on how we can change and prevent DE behaviour in sports. We need to identify psychological constructs that may influence eating behaviour in sport, and how those factors exert their influence. Controlled intervention studies aiming at preventing athletes from developing DE and ED should be conducted. The increasing emphasis on disease prevention and health promotion in the society should be incorporated into the sport culture and research.

Acknowledgements The authors thank the athletes in this study for participating and thereby enabling them to contribute to the research within the field.

Contributors IP had the project idea, developed and executed the study, collected the data, performed the literature search and statistical analysis, interpreted the data, wrote the initial draft of the manuscript and edited it. She is the guarantor. EH helped with the statistics, interpretation of the data and editing of the manuscript. FS helped with interpretation of the data and editing of the manuscript.

Competing interests None declared.

Ethics approval The Regional Committee for Medical and Health Science Ethics in Southern Norway.

Patient consent Obtained.

Provenance and peer review Not commissioned; externally peer reviewed.

Data sharing statement No additional data are available.

Open Access This is an Open Access article distributed in accordance with the Creative Commons Attribution Non Commercial (CC BY-NC 4.0) license, which permits others to distribute, remix, adapt, build upon this work noncommercially, and license their derivative works on different terms, provided the original work is properly cited and the use is non-commercial. See: http:// creativecommons.org/licenses/by-nc/4.0/

\section{REFERENCES}

1. Sigman GS. Eating disorders in children and adolescents. Pediatr Clin North Am 2003;50:1139-17.

2. Martinsen M, Sundgot-Borgen J. Higher prevalence of eating disorders among adolescent elite athletes than controls. Med Sci Sports Exerc 2013;45:1188-97.

3. Miles L. Physical activity and health. Nutr Bulletin 2007;32:314-63.

4. Penedo FJ, Jason R. Exercise and well-being: a review of mental and physical health benefits associated with physical activity. Curr Opin Psychiatry 2005;18(2):189-93.

5. Byrne S, McLean N. Eating disorders in athletes: a review of the literature. J Sci Med Sport 2001;4:145-59.

6. Smolak L, Murnen SK, Ruble AE. Female athletes and eating problems: a meta-analysis. Int J Eat Disord 2000;27:371-80.

7. Torstveit MK, Rosenvinge JH, Sundgot-Borgen J. Prevalence of eating disorders and the predictive power of risk models in female elite athletes: a controlled study. Scand J Med Sci Sports 2008;18:108-18.

8. American Psychiatric Association. Diagnostic and Statistical Manual of Mental Disorders: DSM-5. 5th edn. Arlington, VA: American Psychiatric Publishing, 2013.

9. Hausenblas HA, Carron AV. Eating disorder indices and athletes: an integration. J Sport Exercise Psy 1999;21:230-58.

10. Sundgot-Borgen J, Torstveit MK. Prevalence of eating disorders in elite athletes is higher than in the general population. Clin $J$ Sport Med 2004;14:25-32. 
11. Byrne S, McLean N. Elite athletes: effects of the pressure to be thin. J Sci Med Sport 2002;5:80-94.

12. Sundgot-Borgen J. Risk and trigger factors for the development of eating disorders in female elite athletes. Med Sci Sports Exerc 1994;26:414-19.

13. Fogelholm M, Hiilloskorpi $\mathrm{H}$. Weight and diet concerns in Finnish female and male athletes. Med Sci Sports Exerc 1999;31:229-35.

14. Fulkerson JA, Keel PK, Leon GR, et al. Eating-disordered behaviors and personality characteristics of high school athletes and nonathletes. Int J Eat Disord 1999;26:73-9.

15. Kirk G, Singh K, Getz H. Risk of eating disorders among female college athletes and nonathletes. J Coll Counsel 2001;4:122-32.

16. Martinsen M, Bratland-Sanda S, Eriksson AK, et al. Dieting to win or to be thin? A study of dieting and disordered eating among adolescent elite athletes and non-athlete controls. $\mathrm{Br} J$ Sports Med 2010;44:70-6.

17. Rosendahl J, Bormann B, Aschenbrenner K, et al. Dieting and disordered eating in German high school athletes and non-athletes. Scand J Med Sci Sports 2009;19:731-9.

18. Mussell MP, Binford RB, Fulkerson JA. Eating disorders: summary of risk factors, prevention programming, and prevention research. Couns Psychol 2000;28:764-96.

19. Stice E. Risk and maintenance factors for eating pathology: a meta-analytic review. Psychol Bull 2002;128:825-48.

20. Augestad LB, Flanders WD. Eating disorder behavior in physically active Norwegian women. Scand J Med Sci Sports 2002;12:248-55.

21. Davis $\mathrm{C}$, Kennedy SH, Ravelski E, et al. The role of physical activity in the development and maintenance of eating disorders. Psychol Med 1994;24:957-67.

22. Sundgot-Borgen J, Torstveit MK. Aspects of disordered eating continuum in elite high-intensity sports. Scand J Med Sci Sports 2010;20(Suppl 2):112-21.

23. Garthe I, Raastad T, Refsnes PE, et al. Is it possible to maintain lean body mass and performance during energy-restriction in elite athletes? Med Sci Sports Exerc 2009;41:9.

24. Koutedakis Y, Pacy PJ, Quevedo RM, et al. The effects of two different periods of weight-reduction on selected performance parameters in elite lightweight Oarswomen. Int $J$ Sports Med 1994; 15:472-7.

25. Degoutte $F$, Jouanel $P$, Bègue RJ, et al. Food restriction, performance, biochemical, psychological, and endocrine changes in judo athletes. Int J Sports Med 2006;27:9-18.

26. Slater GJ, Rice AJ, Tanner R, et al. Impact of two different body mass management strategies on repeat rowing performance. Med Sci Sports Exerc 2006;38:138-46.

27. Koral J, Dosseville F. Combination of gradual and rapid weight loss: effects on physical performance and psychological state of elite judo athletes. J Sport Sci 2009;27:115-20.

28. Sundgot-Borgen J, Garthe I. Elite athletes in aesthetic and Olympic weight-class sports and the challenge of body weight and body compositions. J Sport Sci 2011;29:11-114.

29. Bratland-Sanda S, Sundgot-Borgen J, Rosenvinge JH, et al. Physical fitness, bone mineral density and associations with physical activity in females with longstanding eating disorders and non-clinical controls. J Sports Med Phys Fitness 2010;50:303-10.

30. Franko DL, Keshaviah A, Eddy KT, et al. A longitudinal investigation of mortality in anorexia nervosa and bulimia nervosa. Am J Psychiatry 2013;170:917-25.
31. Crow SJ, Peterson CB, Swanson SA, et al. Increased mortality in bulimia nervosa and other eating disorders. Am J Psychiatry 2009;166:1342-6.

32. Bergh U, Forsberg A. Influence of body mass on cross-country ski racing performance. Med Sci Sports Exerc 1992;24:1033-9.

33. Larsson P, Henriksson-Larsén K. Body composition and performance in cross-country skiing. Int $J$ Sports $\mathrm{Med}$ 2008;29:971-5.

34. Stice E, Killen JD, Hayward C, et al. Age of onset for binge eating and purging during adolescence: a four-year survival analysis. $J$ Abnorm Psychol 1998;107:671-5.

35. Woodside DB, Garfinkel P. Age of onset in eating disorders. Int J Eat Disorder 1992;12:31-6.

36. Garner DM. Eating Disorder Inventory-2: professional manual. Odessa, Fla: Psychological Assessment Resources, 1991. IV, 70s. p.

37. Eberenz KP, Gleaves DH. An examination of the internal consistency and factor structure of the Eating Disorder Inventory-2 in a clinical sample. Int J Eat Disord 1994;16:371-9.

38. Thiel A, Paul T. Test-retest reliability of the Eating Disorder Inventory 2. J Psychosom Res 2006;61:567-9.

39. Welch G, Hall A, Norring C. The factor structure of the Eating Disorder Inventory in a patient setting. Int $J$ Eat Disorder 1990;9:79-85.

40. Black DR, Larkin LJ, Coster DC, et al. Physiologic screening test for eating disorders/disordered eating among female collegiate athletes. J Athl Train 2003;38:286-97.

41. Garner DM, Olmsted MP, Polivy J. Comparison between weight-preoccupied women and anorexia nervosa. Psychosom Med 1984:46:255-66.

42. Torstveit MK, Sundgot-Borgen J. The female athlete triad exists in both elite athletes and controls. Med Sci Sports Exerc 2005;37:1449-59.

43. Nichols JF, Rauh MJ, Barrack MT, et al. Disordered eating and menstrual irregularity in high school athletes in lean-build and nonlean-build sports. Int J Sport Nutr Exerc Metab 2007;17: 364-77.

44. Jacobi C, Abascal L, Taylor CB. Screening for eating disorders and high-risk behavior: caution. Int J Eat Disord 2004;35:280-95.

45. Stice E, Shaw HE. Role of body dissatisfaction in the onset and maintenance of eating pathology: a synthesis of research findings. Psychosom Res 2002;53:985-93.

46. Fairburn CG, Cooper Z, Doll HA, et al. Identifying dieters who will develop an eating disorder: a prospective, population-based study. Am J Psychiatry 2005;162:2249-55.

47. Fairburn CG, Harrison PJ. Eating disorders. Lancet 2003;361:407-16.

48. Jacobi C, Hayward C, de Zwaan M, et al. Coming to terms with risk factors for eating disorders: application of risk terminology and suggestions for a general taxonomy. Psychol Bull 2004;130: $19-65$

49. Bardone-Cone AM, Wonderlich SA, Frost RO, et al. Perfectionism and eating disorders: current status and future directions. Clinic Psychol Rev 2007:27:384-405.

50. Royston P, Altman DG, Sauerbrei W. Dichotomizing continuous predictors in multiple regression: a bad idea. Statist Med 2006;25:127-41.

51. Pike KM, Loeb K, Walsh BT. Binge eating and purging. In: Allison DB, ed. Handbook of assessment methods for eating behaviors and weight related problems: measures, theory, and research. Thousand Oaks, CA: Sage Publications, 1995:303-46. 